\title{
The clinical features of 67 patients with clinically definite Steele-Richardson-Olszewski syndrome
}

\author{
V.M.S. de Bruin and A.J. Lees \\ The National Hospital for Neurology and Neurosurgery, Queen Square, \\ London WC1N 3BG, UK
}

\section{Correspondence to: A.J. Lees at above address}

\begin{abstract}
The clinical features of 67 patients with probable Steele-Richardson-Olszewski syndrome have been analysed. Bradykinesia was present in $\mathbf{9 2 . 5 \%}$ of cases at the time of initial assessment and the two commonest presenting complaints were walking difficulties and stiffness. Only 11 patients had a supranuclear gaze palsy when first seen. Forty-nine patients developed cognitive impairment in the course of their illness based on neuropsychological testing. In addition to the classical clinical findings occasional other findings included focal dystonia, tonic inhibition of levator palpebrae and blepharospasm, respiratory disturbances and impaired hearing. Only nine cases responded at all to levodopa therapy.
\end{abstract}

Keywords: Autonomic signs - Brain scan - Breathing difficulty - Dementia - Dystonia - Hearing loss - Sleepiness - Supranuclear palsy

\section{INTRODUCTION}

In 1964, Steele, Richardson and Olszewski described a group of patients with a rigid-akinetic syndrome, supranuclear ophthalmoplegia, axial dystonia, pseudobulbar palsy and variable degrees of mental impairment (Steele $e t$ al., 1964). Subsequently, numerous cases have been reported in the literature (Brusa et al., 1980; Kristensen, 1985; Maher and Lees, 1986), confirming that this entity is a disease of world-wide distribution, occurring in the presenium, relentlessly progressive and leading to death usually within 5-9 years of diagnosis (David et al., 1968; Golbe et al., 1988). Following the original complete anatomo-clinical description, as predicted by Richardson, the clinical and pathological spectrum has been broadened. However, no definitive aetiology has been established nor is any therapy yet available to alleviate substantially the clinical symptoms or alter the course of the illness.

In the absence of a supranuclear down gaze palsy, definitive clinical diagnosis is impossible although the disorder may be suspected. Many cases initially masquerade as Parkinson's disease (PD), or are diagnosed as atypical parkinsonism. Other patients presenting with cognitive impairment or psychiatric symptoms may be thought to have a primary degenerative dementia. In this study, we present the clinical findings in 67 patients diagnosed as Steele-Richardson-Olszewski syndrome (SROS) and seen by one of us (AJL) over a period of 10 years at the National Hospital for Neurology and Neurosurgery, at Queen Square in London.

\section{METHOD}

We reviewed the clinical data of 67 patients clinically diagnosed as SROS over a period of 10 years (1982-1991). The diagnostic criteria used were those defined by Maher and Lees (1986). Twenty-one patients in this series were already included in a previous study (Maher and Lees, 1986). All patients had supranuclear palsy of vertical gaze and at least one of the following features: pseudobulbar palsy, dementia, axial or limb rigidity, bradykinesia, pyramidal signs, or gait disorders. All patients were examined at least once, by one of the authors (AJL). Twenty-four patients are still living, 26 have died and 17 are lost to follow-up. Of the patients who died the mean duration of illness was 5 years (range 3-10 years). At post-mortem, six cases were confirmed as having the histological abnormalities compatible with the diagnosis.

\section{RESULTS}

There were 41 men and 26 women, and the disease first appeared at a mean age of 62 (49-81 years). The most common presenting symptoms were difficulty walking and frequent falls. In decreasing order of frequency, the other most common features were: stiffness, postural tremor, cognitive impairment, slurring of speech, and blurred vision (Table I).

The commonest clinical diagnoses at presentation were either SROS, PD or Parkinson's syndrome, a diagnosis of Alzheimer's disease (AD) being less common (Fig. 1).

Behavioural Neurology . Vol 5.1992 
TABLE I. Initial presenting symptoms in 67 patients diagnosed as SROS

\begin{tabular}{|c|c|c|}
\hline Symptoms & No. patients & $\%$ \\
\hline $\begin{array}{l}\text { Difficult walking, falls and loss of } \\
\text { balance }\end{array}$ & 34 & 50.7 \\
\hline Stiffness & 14 & 20.9 \\
\hline Unilateral postural tremor & 6 & 8.9 \\
\hline $\begin{array}{l}\text { Abnormal behaviour, forgetful- } \\
\text { ness and depression }\end{array}$ & 5 & 7.5 \\
\hline Slurred speech & 4 & 6.0 \\
\hline Blurring of vision & 4 & 6.0 \\
\hline
\end{tabular}

On initial assessment the most frequent physical signs were bradykinesia, rigidity and dysarthria. Supranuclear gaze palsy, a cardinal feature for the diagnosis of SROS, was present in only 11 cases. Other physical signs were: axial dystonia, tremor, dysphagia, frontal, cerebellar and pyramidal signs (the latter considered present only when plantars were extensor), antecollis, blepharospasm, lid levator inhibition and segmental dystonia (Table II).

Excessive daytime sleepiness and severe snoring occurred in 11 patients. Sleep studies showed sleep apnoea and $\mathrm{CO}_{2}$ retention in three out of four cases. Laryngoscopy of three patients showed two to have laryngeal muscle incoordination.

All patients had levodopa therapy at some stage of their illness and in nine cases the clinical response was considered to be initially good but unsustained.

Ancillary investigations carried out in some patients included audiogram, tests of autonomic function, brainstem auditory evoked response (BAER) and brain scan (Table III). Autonomic testing carried out in 33 subjects
TABLE II. Frequency of physical signs at initial and at final assessment in 67 patients with SROS

\begin{tabular}{|c|c|c|c|c|}
\hline \multirow[t]{2}{*}{ Physical sign } & \multicolumn{2}{|c|}{$\begin{array}{c}\text { First assessment } \\
3(2-4) \text { years }\end{array}$} & \multicolumn{2}{|c|}{$\begin{array}{l}\text { Last assessment } \\
5(3-9) \text { years }{ }^{1}\end{array}$} \\
\hline & No. patients & $\%$ & No. patients & $\%$ \\
\hline Bradykinesia & 62 & 92.5 & 67 & 100 \\
\hline Rigidity & 45 & 67.1 & 55 & 82.0 \\
\hline Dysarthria & 17 & 25.4 & 47 & 70.1 \\
\hline Axial dystonia & 12 & 17.9 & 49 & 73.1 \\
\hline Supranuclear gaze palsy & 11 & 16.4 & 67 & 100 \\
\hline Postural tremor & 9 & 13.4 & 15 & 22.4 \\
\hline Pyramidal signs & 5 & 7.5 & 34 & 50.7 \\
\hline Dysphagia & 3 & 4.5 & 36 & 53.7 \\
\hline Frontal signs & 3 & 4.5 & 46 & 68.6 \\
\hline Cerebellar signs & 2 & 3.0 & 10 & 14.9 \\
\hline Antecollis & 1 & 1.5 & 6 & 11.3 \\
\hline Blepharospasm & 1 & 1.5 & 15 & 22.4 \\
\hline Lid levator inhibition & 1 & 1.5 & 17 & 25.4 \\
\hline Segmental dystonia & 1 & 1.5 & 21 & 31.3 \\
\hline
\end{tabular}

'Mean (range) duration of disease.

showed seven had an impaired cardiovascular response although none of the patients had clinical signs of autonomic failure. In only one case was there evidence of delayed response in central pathways on BAER showing central vestibular abnormalities involving multiple connections including the basal ganglia and cerebellum. Brain scans frequently showed involutional changes in the cerebrum and in 15 patients subcortical zones of low attenuation suggesting white matter lesions were verified (Table IV).

In the retrospective analysis of mental symptoms, dementia was defined using the DSM-III-R criteria

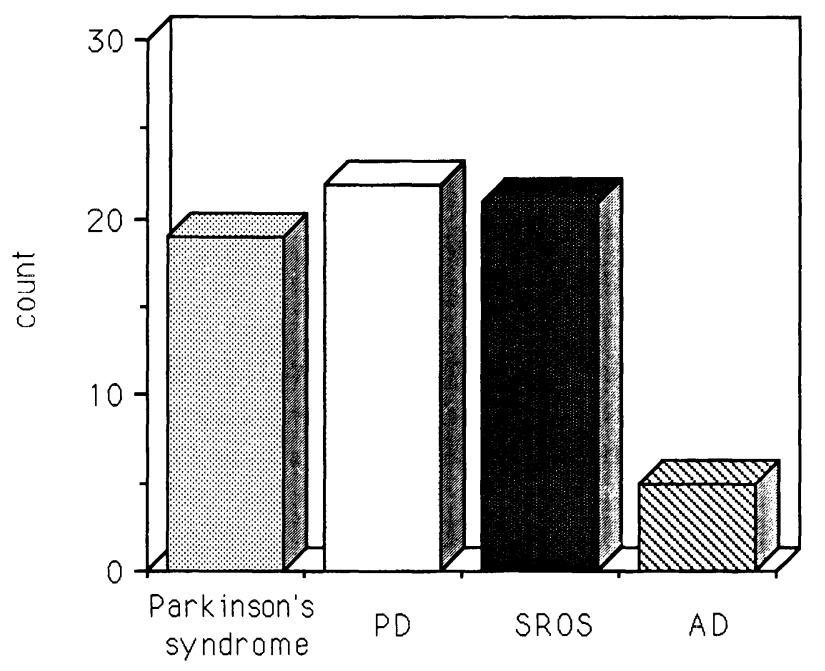

FIG. 1. Clinical diagnosis at presentation of illness in 67 patients with SROS. 
TABLE III. Results of investigation of 67 patients diagnosed as SROS

\begin{tabular}{lccc}
\hline Investigation & No. studied & Normal & Abnormal \\
\hline Audiogram & 18 & 11 & 7 \\
Autonomic test & 33 & 26 & 7 \\
BAER & 10 & 9 & 1 \\
Brain scan & 62 & 18 & 44 \\
\hline
\end{tabular}

TABLE IV. Severity and type of brain scan abnormality in 44 patients with SROS

\begin{tabular}{lcc}
\hline & No. patients & $\%$ \\
\hline Mild cortical atrophy & 17 & 38.6 \\
Severe cortical atrophy & 27 & 61.4 \\
(Brainstem and cerebellar atrophy & 12 & $27.2)$ \\
\hline
\end{tabular}

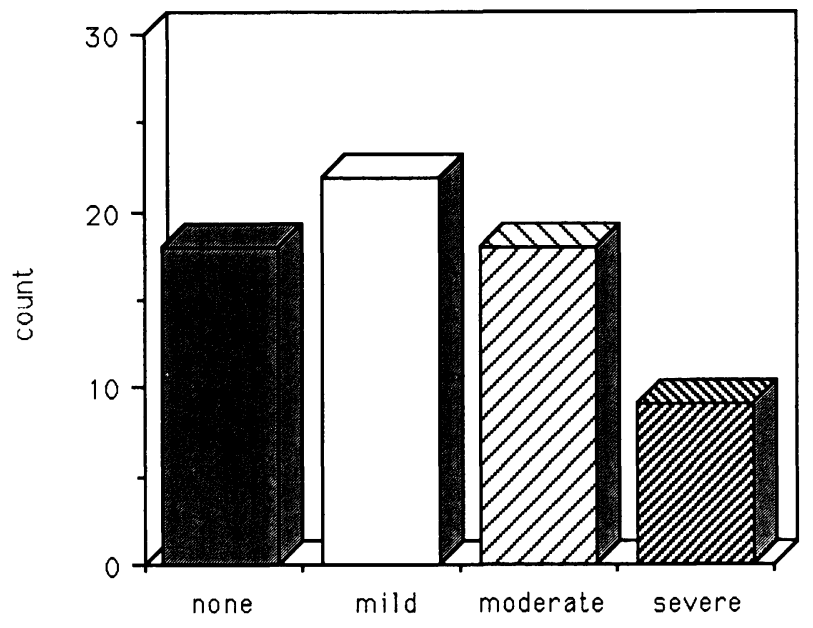

FIG. 2. Severity of dementia in 67 patients with SROS according to DSM-III-R criteria.

(American Psychiatric Association, 1987). Some patients had no mental impairment, while others had severe cognitive deterioration (Fig. 2).

Psychological test scores of 44 patients showed a mean (S.D.) verbal intelligence quotient (VIQ) of 97.6 (10.3) and a performance intelligence quotient (PIQ) of 92.8 (14.2). Loss of memory, deterioration of intellectual function, slowness of thought, diminished capacity to manipulate acquired knowledge, change of personality and aggressiveness were some of the clinical findings on psychological assessment.

\section{DISCUSSION}

The clinical features described in this series of cases broadly correspond to those reported in other large series (Maher and Lees, 1986; Golbe et al., 1988). Dysarthria was an early and severe symptom in most cases. Leg dystonia was a frequent physical sign in 21 cases and six patients had a flexed rather than hyperextended posture. The autonomic abnormalities in cardiovascular reflex were relatively uncommon and could have been due to ageing effects more than the disease process.

Despite the widespread neurofibrillary degeneration occurring in the brainstem in SROS, the BAER results were normal in most patients reflecting an intact auditory pathway (Tolosa and Zeese, 1979). In only one case out of nine was there a delay in conducting time as well as central vestibular abnormalities involving multiple connections including the basal ganglia and cerebellum.

Considerable controversy exists about the incidence of dementia in SROS (Albert et al., 1974; Maher et al., 1985; Litvan et al., 1989). Our data show that very few patients were free of mental impairment. Common complaints were abnormal behaviour, personality changes, poor memory, emotional lability, depression and social withdrawal. Five patients presented with severe neuropsychiatric symptoms leading to an initial misdiagnosis of $\mathrm{AD}$ (Fig. 1). Early aphasia, apraxia and agnosia were never observed. Severity of dementia did not correlate with age, duration of illness or brain scan abnormalities. Neuropsychological examination was carried out in 44 cases. Using the values for an age-matched normal population published by Fisk et al. (1982), verbal and performance IQ were below those expected for controls. Although severe dysarthria and visual difficulties can impair performance, this large series demonstrates that intellectual impairment can be detected in most patients. 


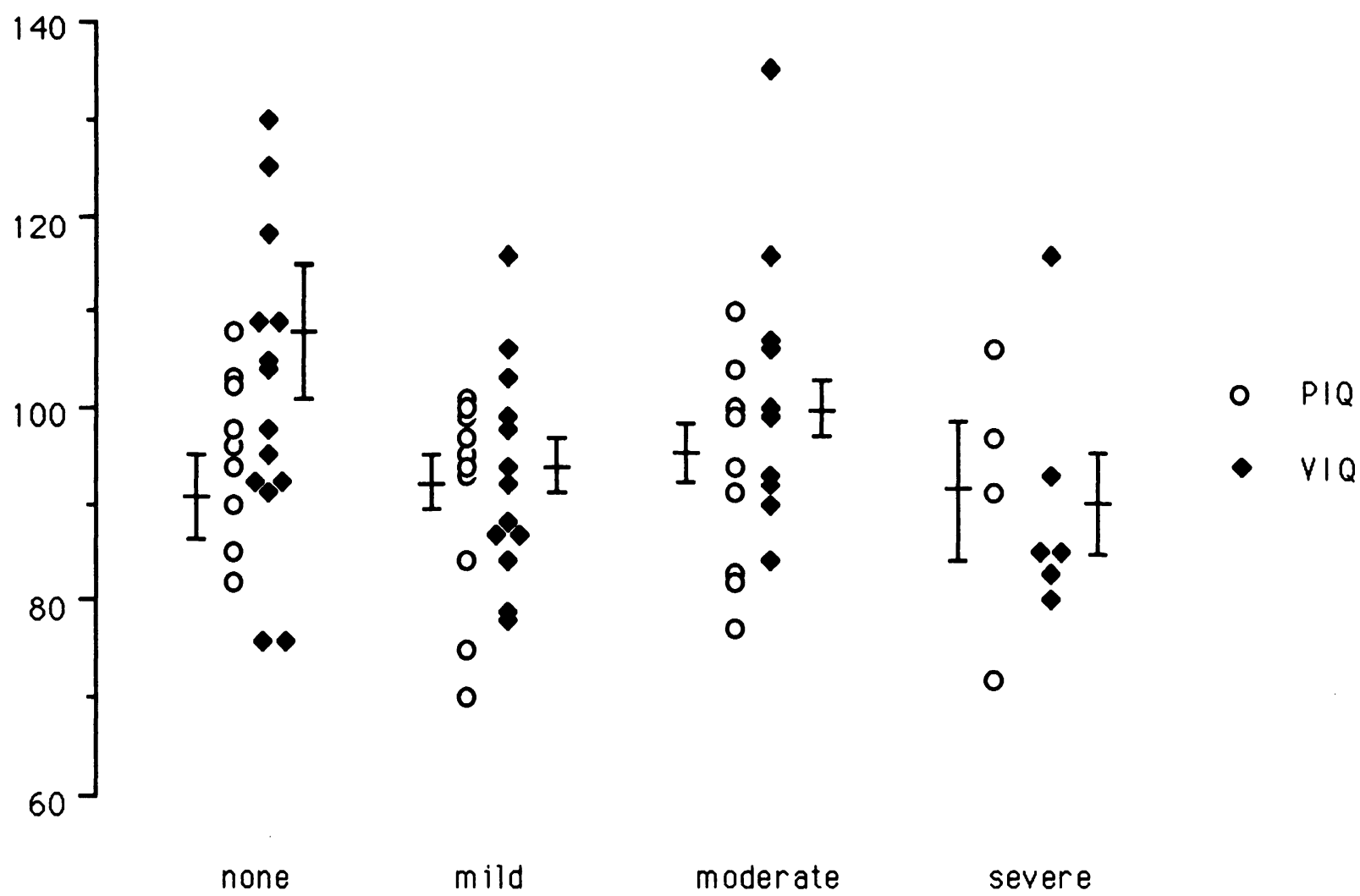

FIG. 3. Performance and verbal IQ by severity of dementia according to DSM-III-R criteria in 44 patients with SROS.

Although only patients with classical features of SROS were included in this review, clinicians must now recognize that cases with identical pathology to that described in SROS may present with a dementing illness without motor signs and a parkinsonian syndrome without supranuclear gaze palsy.

\section{Acknowledgements}

Dr V.M.S. de Bruin is supported by Conselho Nacional de Desenvolvimento Cientifico e Tecnológico-CNPq of Brazil. The authors are indebted to Miss R. Nani for her invaluable assistance.

\section{REFERENCES}

Albert ML, Feldman RG and Willis AL (1974) The subcortical dementia of progressive supranuclear palsy. Journal of Neurology, Neurosurgery and Psychiatry, 37, 121-130.

American Psychiatric Association (1987) Diagnostic and Statistical Manual of Mental Disorders, revised 3rd edn, DSMIII-R. APA, Washington, DC.

Brusa A, Mancardi GL and Bugiani O (1980) Progressive supranuclear palsy 1979: an overview. Italian Journal of Neurological Science, 4, 205-222.
David NJ, Mackey EA and Smith JL (1968) Further observations in progressive supranuclear palsy. Neurology, 18, 349-356.

Fisk JD, Goodale MA, Burkhart G and Barnett HJM (1982) Progressive supranuclear palsy: The relationship between ocular motor dysfunction and psychological test performance. Neurology, 32, 698-705.

Golbe LI, Davis PH, Schonberg BS and Duvoisin RC (1988) Prevalence and natural history of progressive supranuclear palsy. Neurology, 38, 1031-1034.

Kristensen MO (1985) Progressive supranuclear palsy-20 years later. Acta Neurologica Scandinavica, 71, 177-189.

Litvan I, Grafman J, Gomez C and Chase TN (1989) Memory impairment in patients with progressive supranuclear palsy. Archives of Neurology, 46, 765-767.

Maher ER and Lees AJ (1986) The clinical features and natural history of the Steele-Richardson-Olszewski syndrome (progressive supranuclear palsy). Neurology, 36, 1005-1008.

Maher ER, Smith EM and Lees AJ (1985) Cognitive deficits in the Steele-Richardson-Olszewski syndrome (progressive supranuclear palsy). Journal of Neurology, Neurosurgery and Psychiatry, 48, 1234-1239.

Steele JC, Richardson JC and Olszewski J (1964) Progressive supranuclear palsy. Archives of Neurology, 10, 333-359.

Tolosa ES and Zeese JA (1979) Brainstem auditory evoked responses in progressive supranuclear palsy. Neurology, 6, 369 . 




The Scientific World Journal
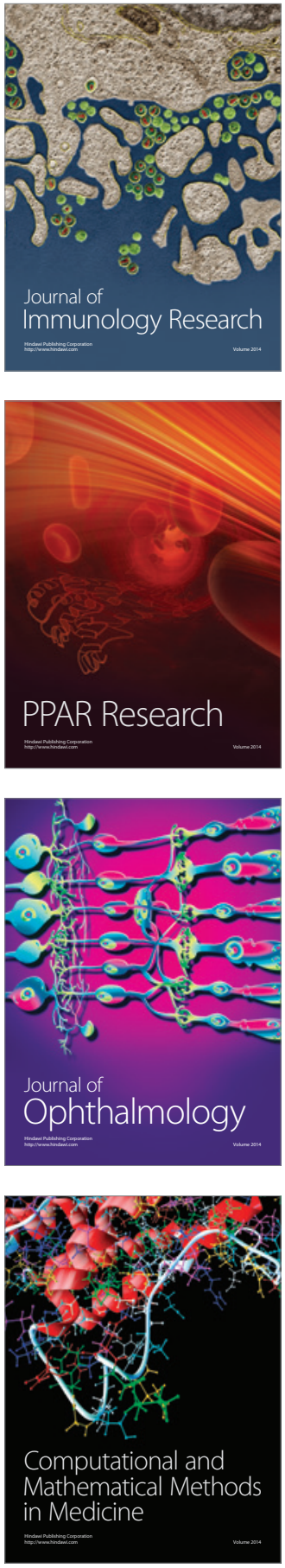



Gastroenterology

Research and Practice
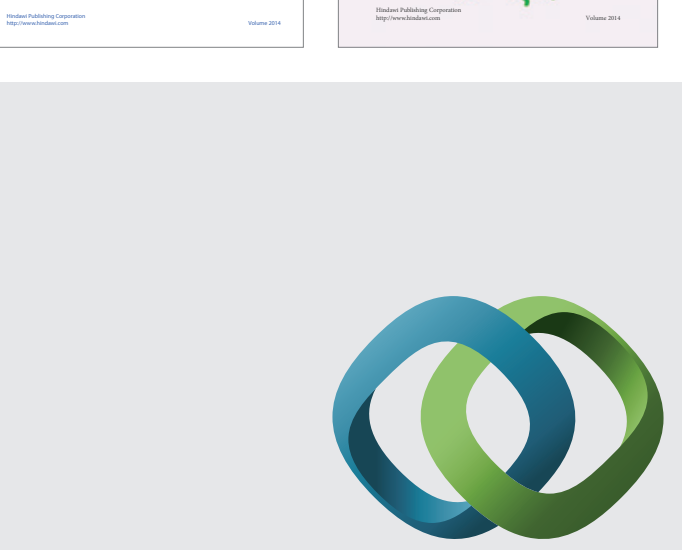

\section{Hindawi}

Submit your manuscripts at

http://www.hindawi.com


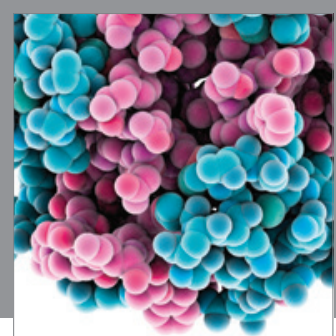

Journal of
Diabetes Research

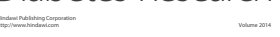

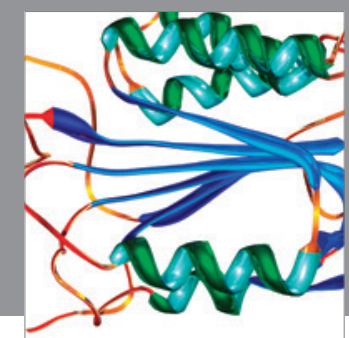

Disease Markers
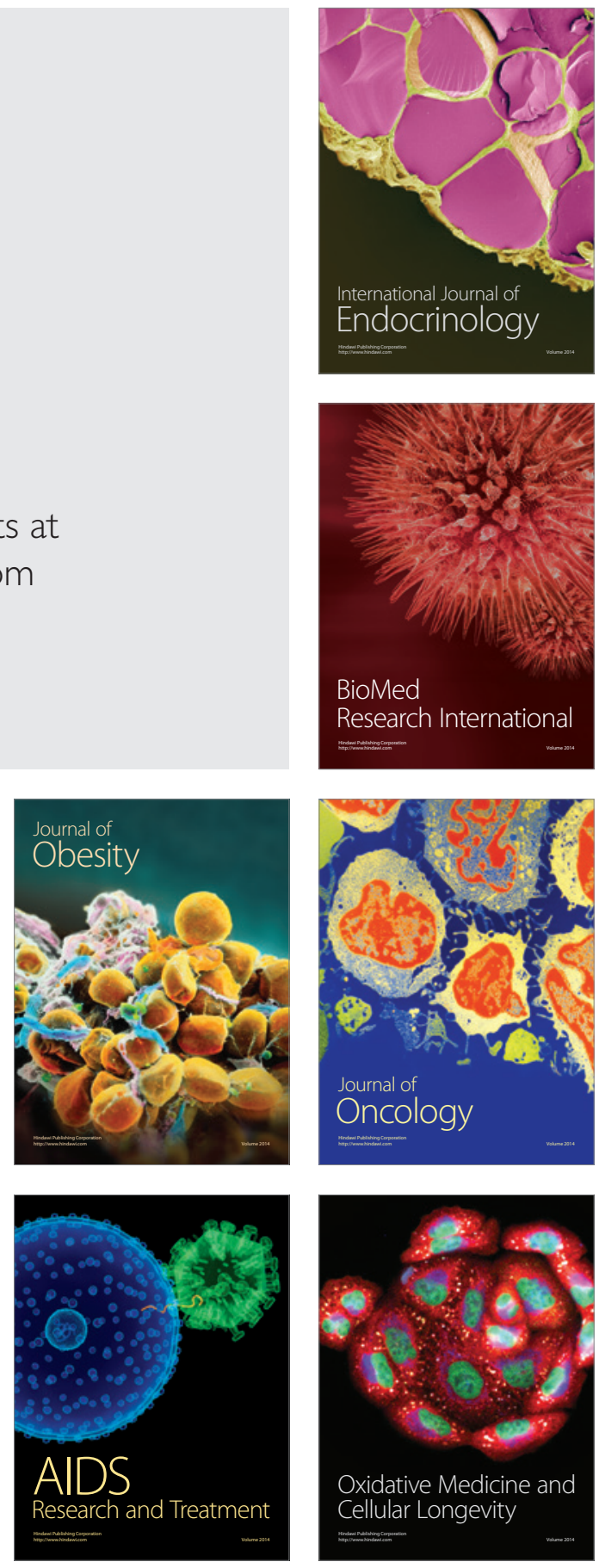